\title{
Cholinergic Septal Grafts into the Hippocampal Formation Improve Spatial Learning and Memory in Aged Rats by an Atropine-Sensitive Mechanism
}

\author{
Fred H. Gage* and Anders Björklund $\dagger$ \\ *Department of Neurosciences, University of California, San Diego, La Jolla, California 92093, and †Department \\ of Hislology, University of Lund, Lund, Sweden
}

Behaviorally impaired old rats were selected from a population of 75 21- to 23-month-old rats on the basis of the place-investigated abilities in the Morris' water-maze task. After the pretransplant test, half of the old impaired rats received bilateral intrahippocampal cell suspension grafts prepared from the fetal septal-diagonal band region, which is rich in developing cholinergic neurons; the other half were left as sham-operated controls. Twelve weeks after grafting, the rats were retested in the water-maze using alternating cue-navigation and place-navigation trials (i.e., with visible or nonvisible escape platform). While the old impaired controls had deteriorated further between the 2 tests and showed poor retention of the pretransplant performance level, the grafted rats were significantly improved in comparison with both their pretransplant performance and the performance of the old impaired controls in the posttransplant test. The graft-induced effect was due both to an improved retention of the performance level acquired in the test performed prior to transplantation surgery, and to an improved acquisition of spatial memory of the escape platform site during the posttransplant test week (measured as an improved focusing of search over the platform site after platform removal). The acetylcholine esterase inhibitor physostigmine had no or only marginal effects on the performance of any of the young or aged rat groups. By contrast, the recovered navigational abilities and spatial memory in the grafted animals were completely abolished after administration of the muscarinic receptor antagonist atropine. A similar atropine-sensitivity was seen in behaviorally nonimpaired aged rats but not in the well-trained young control rats.

The results show that cholinergic septal grafts, implanted into the hippocampal formation, improved spatial learning in the impaired aged rats primarily, or perhaps exclusively, by a recovery of the rats' ability to use spatial cues for place-navigation in the water-maze, while other aspects of the performance deficits in the water-maze task in the aged rats were left unaffected by the septal grafts. On the basis of parallel morphological studies, it is proposed that the effects of the septal grafts on the spatial learning impairments in the aged rats are critically dependent on the direct action of cholinergic neurons in the grafts via synapses formed onto neuronal elements in the host by their ingrowing axons.

\footnotetext{
Received Sept. 30, 1985; revised Feb. 28, 1986; accepted Mar. 28, 1986.

We thank Carine Jonsson, Birgit Haraldsson, Agneta Persson, and Gertrude Stridsberg for excellent technical assistance, and Siv Carlson for typing the manuscript. The study was supported by grants from the National Institutes of Aging (AG 03766) and the Swedish Medical Research Council (04X-4493).

Correspondence should be addressed to Fred H. Gage, Department of Neurosciences, M-024, University of California, San Diego, La Jolla, CA 92093.

Copyright (C) 1986 Society for Neuroscience $0270-6474 / 86 / 102837-11 \$ 02.00 / 0$
}

Grafts of fetal ventral forebrain, rich in developing cholinergic neurons, are capable of reinnervating large areas of the hippocampal formation or neocortex in young rats with denervating brain lesions (Björklund and Stenevi, 1977; Björklund et al., 1983a, b; Fine et al., 1985b; Kromer, 1985; Lewis and Cotman, 1983). In the hippocampal formation the grafted cholinergic neurons have been shown to be biochemically active (Björklund et al., 1983b) and to establish electrophysiologically and morphologically normal synapses with neuronal elements of the host, including granule cells and pyramidal cells, in the dentate gyrus and the CA1 area (Clarke et al., 1985a; Low et al., 1983; Segal et al., 1985). In animals with fimbria-fornix lesions that transect the septohippocampal projection system, septal grafts have been shown to restore normal hippocampal functional metabolic rates, as assessed by autoradiographic measurements of regional 2-deoxyglucose utilization (Kelly et al., 1985), and they have been shown to promote behavioral recovery in hippocampus-dependent spatial learning in different types of radial maze tasks (Dunnett et al., 1982; Low et al., 1982, 1985). Similarly, grafts of ventral forebrain cholinergic neurons, implanted into the frontoparietal cortex of rats with excitotoxic lesions of the nucleus basalis region, have been found to ameliorate both sensorimotor and learning impairments in the lesioned rats (Dunnett et al., 1985; Fine et al., 1985a).

The ability of the cholinergic septal grafts to substitute, morphologically and functionally, for the loss of a cholinergic pathway in young brain-damaged rats has raised the question of whether similar effects could also be obtained in aged rats, in which defects in learning and memory have been associated with an age-dependent decline in parameters of forebrain cholinergic functions (Bartus et al., 1982; Gibson et al., 1981; Lippa et al., 1980, 1981; Sherman et al., 1981; Sims et al., 1982; Strong et al., 1980). Although there are no data to implicate an actual loss of cholinergic forebrain neurons with age in rodents, similar to that which occurs in Alzheimer's type dementia in man (see Bartus et al., 1982; Coyle et al., 1983), it seems likely that a functional deterioration of the limbic and cortical cholinergic projection systems contributes to the age-related cognitive impairments also in these species as well.

Previous studies from our laboratory (Gage et al., 1983, 1984a) have shown that grafts obtained from the developing septaldiagonal band region in rat fetuses and implanted into the depth of the hippocampus in the form of a dissociated cell suspension survive just as well in old (about 2 year old) as in young recipient rats. Despite the fact that the host hippocampus is left intact, without any denervating lesion, the AChE-positive (presumably cholinergic) neurons in the graft extend a new terminal network into the host hippocampal CA1 and CA3 areas and dentate gyrus. Electron microscopy, using choline acetyltransferase immunocytochemistry (Clarke et al., 1985b), has provided evi- 
dence that the ingrowing graft axons establish extensive and morphologically mature synaptic contacts on several types of neuronal elements in the host.

In a recent study (Gage et al., 1984a), we reported that septal suspension grafts, implanted into the hippocampus in this way, can ameliorate spatial learning impairments in aged rats, as assessed in the Morris' place-navigation task (Morris, 1981, 1984). In the present series of experiments we have analyzed this behavioral effect in further detail, using a test procedure with alternating nonvisible and visible platform, testing the rats' abilities for both place-navigation and cue-navigation in the pool. Furthermore, we have sought to characterize pharmacologically the cholinergic involvement in the graft-induced effect through the administration of the AChE inhibitor, physostigmine, and the muscarinic cholinergic receptor blocker, atropine, to the grafted animals. Atropine has previously been shown to block the acquisition of place-navigation, but not cue-navigation, in young rats in the Morris' water-maze task (Sutherland et al., 1982a; Wishaw, 1985; Wishaw et al., 1985). The results show that aged rats that are severely impaired in the water-maze are deficient both in place- and cue-navigation, and that they are only marginally affected by physostigmine or atropine pretreatment. Septal grafts improve spatial learning in the impaired aged rats primarily, or perhaps exclusively, by a recovery of the rats' ability to use spatial cues in the water-maze, and this graftinduced place-navigational ability is completely abolished by atropine pretreatment.

\section{Materials and Methods}

\section{Subjects}

Female rats of the Sprague-Dawley strain (ALAB, Stockholm, Sweden) were used. Aged rats were obtained as retired breeders at 9-11 months of age. They were housed in a clean controlled environment for an additional 12 months before the experiment started, at which time they were 21-23 months of age. The young control rats were bought at 2 months of age and were allowed to adapt to the new environment for $3-5$ weeks before the start of the experiment. The rats were housed in groups of 4-6 animals per cage under a 12:12 hr light-dark cycle, with ad lib access to food and water throughout the experiment. All testing was conducted during the rats' daylight period.

\section{Experimental design}

Thirty-one young (3-month-old) and 75 old (21- to 23-month-old) rats were first screened behaviorally, over $5 \mathrm{~d}$, in the Morris' water-maze task (pretransplant test). From the aged group, 24 behaviorally impaired and 8 nonimpaired rats were selected on the basis of their acquisition of the place-navigation task (see Results). Two to five weeks after the pretransplant test, 10 of the "old impaired" rats received bilateral septal suspension transplants in the hippocampal formation, and 10 received similar sham injections. The remaining 4 "old impaired" rats were not included in the present study. Twelve weeks later, i.e., when the young rats were about 6 months of age and the old rats werc 25-27 months of age, the rats were again tested in the water-maze task, for $5 \mathrm{~d}$ without drug treatment (posttransplant test) and then, 1 week later, for $4 \mathrm{~d}$ with physostigmine and atropine pretreatment (drug test).

Thirteen old impaired rats that survived throughout the experiment (7 with septal grafts and 6 without) were finally taken for microscopic analysis using choline acetyltransferase (ChAT) immunocytochemistry (Clarke et al., 1985b). These rats were subjected to a unilateral aspirative fimbria-fornix lesion (see Björklund and Stenevi, 1977; Gage et al., 1983) $7 \mathrm{~d}$ before sacrifice in order to remove the intrinsic septohippocampal cholinergic input and thus unmask the graft-associated ChATpositive fiber outgrowth in the ChAT-stained sections in the hippocampal formation on one side.

\section{Transplantation surgery}

Septal suspension grafts were prepared according to the method of Björklund et al. (1983c). The developing septal-diagonal band area was dissected from the ventral forebrain of E14-E16 donor rat fetuses (crownrump length, $12-16 \mathrm{~mm}$ ) of the same inbred rat strain. Tissue from 10
15 fetuses was collected in sterile $0.6 \%$ glucose-saline at room temperature. The tissue was then incubated in trypsin (Sigma, Type II; 0.1\% in the glucose-saline medium) for $15-20 \mathrm{~min}$ at $37^{\circ} \mathrm{C}$, washed $4-5$ times with fresh glucose-saline, and mechanically dissociated in $100 \mu \mathrm{l}$ of this medium to form a milky cell suspension. Three $3 \mu \mathrm{l}$ aliquots were injected stereotaxically into the hippocampus on each side under ketamine-xylazine anesthesia $(10 \mathrm{mg} / \mathrm{kg}$ Ketalar, Parke-Davis, and $5 \mathrm{mg} /$ kg Rompun, Hoechst, i.p.), at the following coordinates: (1) $\mathrm{A}=+4.5$ $\mathrm{mm}$ from the interaural line, $\mathrm{L}= \pm 3.5 \mathrm{~mm}, \mathrm{~V}=3.0 \mathrm{~mm}$ from dura; (2) $\mathrm{A}=+3.0 \mathrm{~mm}, \mathrm{~L}= \pm 3.7 \mathrm{~mm}, \mathrm{~V}=3.7 \mathrm{~mm}$; and (3) $\mathrm{A}=+3.0 \mathrm{~mm}$, $\mathrm{L}= \pm 4.8 \mathrm{~mm}, \mathrm{~V}=5.7 \mathrm{~mm}$, with the incisor bar set at the interaural line. Each injection was performed over 5 min.

\section{Behavioral testing}

The rats were tested in the Morris' water-maze task (Morris, 1981, 1984) prior to transplantation, and again at 12 weeks after transplantation. The water-maze pool was a circular tank, made of gray plastic, $140 \mathrm{~cm}$ in diameter and $45 \mathrm{~cm}$ deep. The pool was located in a corner of a room rich in extra-maze cues (e.g., window, lamps, water tap, experimenter's table with video monitors) that were available for the rats to use in locating the escape platform. The pool was filled to a depth of $30 \mathrm{~cm}$ with water made opaque by the addition of about 0.5 liter dried milk powder and was maintained thermostatically at $26^{\circ} \mathrm{C}$.

Four equally spaced points around the edge of the pool were designated as start positions, and these points divided the pool into 4 quadrants. The escape platform was kept in a constant position in the middle of one quadrant, midway between the edge and the center. The rats were trained for 2 blocks of 4 trials on each day for 5 consecutive days. Within each block of trials, all 4 start positions were used in a pseudorandom sequence. The rats were trained for both place-navigation and cue-navigation (Morris, 1984) using nonvisible and visible escape platform on alternating trials (trials $1-3-5-7$ being visible and trials 2-4-6-8 being nonvisible). This design made it possible to analyze the rats' ability to learn to find the platform both with the use of local cues (visible platform) and in the absence of any local cues, when the rats have to navigate according to distant spatial cues in the surrounding environment (nonvisible platform). The nonvisible platform was an $11 \times 11$ $\mathrm{cm}$ transparent plastic plate mounted on a solid column $1 \mathrm{~cm}$ below the water surface. The platform was made visible by placing an additional 3-cm-thick wooden platform (with a 5-cm-tall vertical rod in the middle) over this platform on the cue-navigation trials.

On each trial the rats were placed in the water facing the wall at the designated start position. The swim path, swim speed, and latency to escape onto the platform were monitored on-line with a digitized TV system connected to an ABC 800 microprocessor. The TV camera was mounted vertically above the center of the pool, and the rat was made detectable by means of a small black plastic hood attached around its neck. Upon finding and climbing onto the platform, the rat was left there for $30 \mathrm{sec}$ until the start of the next trial. If a rat failed to find the platform within $60 \mathrm{scc}$, it was removed from the water and placed onto the platform for $30 \mathrm{sec}$ and allocated a swim latency score of $60 \mathrm{sec}$. On the fifth day the second block of trials was replaced by a single "spatial probe" trial. The platform was removed from the pool, and both the swim path and the distance swum in each of the 4 quadrants were recorded over $60 \mathrm{sec}$. The number of times the rat swam through the area where the platform had been located on previous trials ("platform crossings") was also registered.

\section{Drug tests}

One week after the posttransplant test the rats were given a further $4 \mathrm{~d}$ of testing in order to study the effects of physostigmine and atropine on place- and cue-navigation in the water-maze pool. On each day the rats were given 2 blocks of 4 trials with alternating visible and nonvisiblc platform, as above, followed by a ninth "spatial probe" trial in which the platform was removed and the rats' swim path was traced over 2 $\mathrm{min}$. On the first day the rats were tested without drug pretreatment ("no drug test"). On the second day each rat was given an injection of $0.05 \mathrm{mg} / \mathrm{kg}$, i.p., of physostigmine (eserine salicylate; Sigma) $15 \mathrm{~min}$ before the start of the test ("physostigmine test"). On the third day the rats received an injection of an equal volume of $\mathrm{NaCl} 15 \mathrm{~min}$ before the start of the test (" $\mathrm{NaCl}$ test"). On the fourth day each rat was given an i.p. injection of $50 \mathrm{mg} / \mathrm{kg}$ atropine sulfate (Sigma) $15 \mathrm{~min}$ before the start of the test ("atropine test"). 

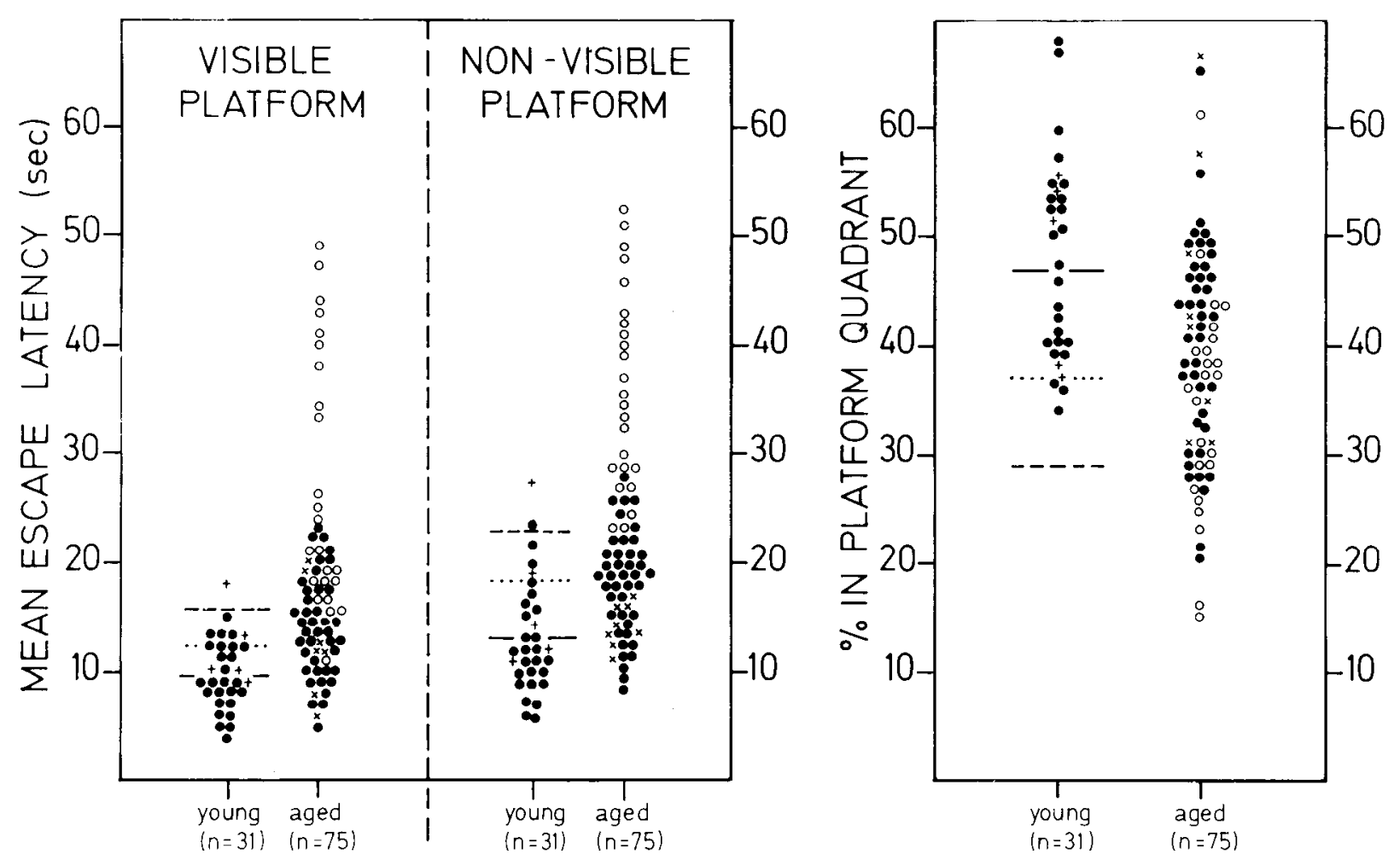

Figure 1. Pretransplantation "screening" test: Mean escape latency (in sec) over all trials for all aged $(n=75)$ and young $(n=31)$ rats in the 1 week pretransplantation test. Left, visible platform (cue-navigation); middle, nonvisible platform (place-navigation); right, percentage swim distance in platform quadrant during the "spatial probe" test. Solid line gives the mean values for young controls, dotted lines indicate 1 SD, and dashed lines indicate 2 SD of the means. Open circles represent the animals selected for the old impaired group and crosses the rats selected for the old nonimpaired group. Plus signs indicate young animals randomly chosen to follow through the experiment. Solid circles indicate remaining animals not used in this study.

\section{Statistical analysis}

Two- or one-way analysis of variance was used when appropriate. When statistical differences were obtained at the $p<0.05$ level, post hoc analysis was performed to determine individual differences between groups, tests, or treatments. For repeated measures, paired comparison $t$ test was used (related $t$ test), and for between-group differences, NewmanKeuls test was applied.

\section{Results}

\section{Behavioral screening of the aged rat group}

Seventy-five old (21- to 23-month-old) and 31 young (3-monthold) rats were screened in the pretransplant test in order to select the "impaired" and the "nonimpaired" old rats for the subsequent transplantation study. Consistent with previous results (Gage et al., 1984a-c), the old rats as a group were significantly impaired on the place-navigation trials, with nonvisible escape platform, both with respect to their acquisition of the task, measured as the mean escape latency (i.e., the time it took for the rats to find the hidden platform in the pool over the $5 \mathrm{~d}$ of testing; middle panel in Fig. 1) and with respect to their spatial memory, measured as thcir ability to locatc the previous platform site in the final "spatial probe" trial, after the platform had been removed on the 5 th day (right panel in Fig. 1). In the present experiment the rats were also tested for cue-navigation, i.e., in alternating trials with a visible escape platform. The aged rats were also impaired on the acquisition of this task. Thus, even when the platform was visible above the water surface in the pool, the aged rats as a group had significantly longer escape latencies than the young (3-month-old) rats (left-hand panel in Fig. 1). Swim speed was only marginally different in the aged and young rat groups (as illustrated for subgroups of rats in Fig. 5). Thus, the impaired performance of the aged rats in both the place-navigation and cue-navigation trials was not due to an overall motor deficit, but to an impaired ability of the aged rats to learn to find the platform over the $5 \mathrm{~d}$ of testing. Both the young and the old rat groups showed significantly better acquisition on the cue-navigation than the place-navigation trials (Fig. 2).

\section{Selection of animals for the transplantation study}

From the scatter-plots of the mean escape latencies in Figure 1, and of the percentage distribution of the swim path in the search for the platform site in the final "spatial probe" test in Figure 1 , it is evident that the performance of the individual rats varied greatly within the aged group. Based on the performance of the young rats, we set the criterion for "impaired" performance in the aged rats such that the mean escape latency on the placenavigation trials (with nonvisible platform) should be at least 2 SD above the mean in the young group (i.e., above $23.5 \mathrm{sec}$; dashed line in the middle panel of Fig. 1). Similarly, we set the criterion for "nonimpaired" performance in the aged rats such that the mean escape latency on the place-navigation trials should be within $1 \mathrm{SD}$ of the mean in the young group (i.e., below 18.4 $\mathrm{sec}$, dashed line in the middle panel in Fig. 1). According to this definition, 31 of the 75 aged rats $(41 \%)$ were impaired, and 26 of the $75(35 \%)$ were nonimpaired. For the subsequent transplantation study, 24 of the impaired rats (open circles in Fig. 1) and 8 of the nonimpaircd rats (crosses in Fig. 1) were selected. In addition, 5 young rats (plus symbols in Fig. 1) were randomly picked from the young group as a young control group.

Applying the same criteria to the performance on the cuenavigation trials, with visible platform, all but 1 of the 24 rats 


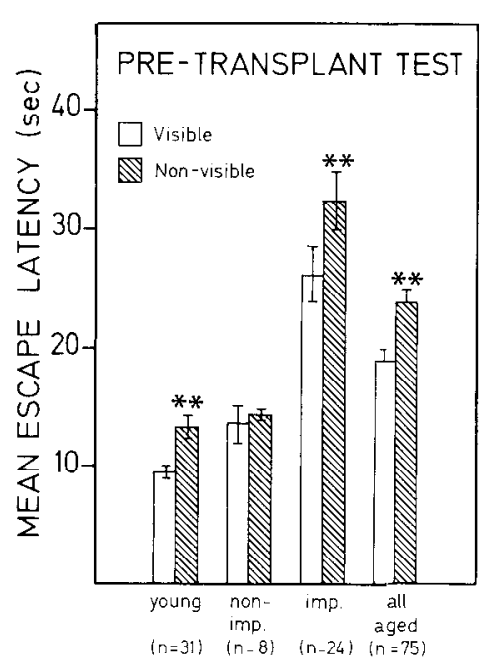

Figure 2. "Screening" breakdown: Mean escape latency (in sec) over all trials in the I week pretransplantation test for all aged $(n=75)$ and young ( $n=31)$ animals. The 2 selected subgroups, the old nonimpaired $(n=8)$ and the old impaired rats $(n=24)$, are also presented for comparison. ${ }^{* *} p<0.01$ indicates differences between performance on visible and nonvisible platform trials.

in the old impaired group were also impaired in cue-navigation (mean escape latency $>13.7 \mathrm{sec}$; dashed line in the left-hand panel in Fig. 1), whereas 3 of the 8 rats in the nonimpaired group were impaired in the cue-navigation task (mean latencies between 19 and $20 \mathrm{sec}$ ). The overall performance of the rats selected for the "old impaired" and the "old nonimpaired" groups is illustrated in Figure 2. While the rats in the impaired group differed significantly on the visible and nonvisible platform ( $p<0.01$; related $t$ test), the rats selected for the nonimpaired group did not.

The distance swum in the platform quadrant, expressed as the percentage of the total swim distance (illustrated in the right panel in Fig. 1), can be taken as a measure of the rats' spatial memory in the localization of the platform site after platform removal on the last day of testing. Fewer of the aged rats were impaired on this index of spatial memory: 15 of the 75 rats $(20 \%)$ had scores within 2 SD of the mean of the young group (dashed line in Fig. 1) and 25 of the aged rats (33\%) had scores below any individual in the young group (i.e., below $34 \%$ ). If the latter limit is used as a criterion for impaired spatial memory, then 11 of the 24 rats in the selected old impaired group (which were selected on the basis of their impaired acquisition of the place-navigation task, see above) were also impaired on this measure (open circles in Fig. 1B).

\section{Graft-induced effects on the acquisition of place- and cue- navigation in the water-maze}

Ten of the 20 old impaired rats used received bilateral septal suspension transplants in the hippocampal formation, and 10 were left as nongrafted controls. The 8 rats in the old nonimpaired group and the 5 young controls were left nongrafted. At the time of posttransplantation testing, 12 weeks after transplantation, 7 of the old impaired rats with septal grafts, 6 of the old impaired nongrafted rats, 5 of the old nonimpaired rats, and all 5 young rats were still alive.

Figure 3 summarizes the acquisition in the cue-navigation (visible platform) and the place-navigation (nonvisible platform) trials in the pre- and posttransplantation tests for the surviving animals. In the pretransplant test, the 2 old impaired groups (open and filled circles) performed significantly worse than both the young controls and the old nonimpaired rats, both
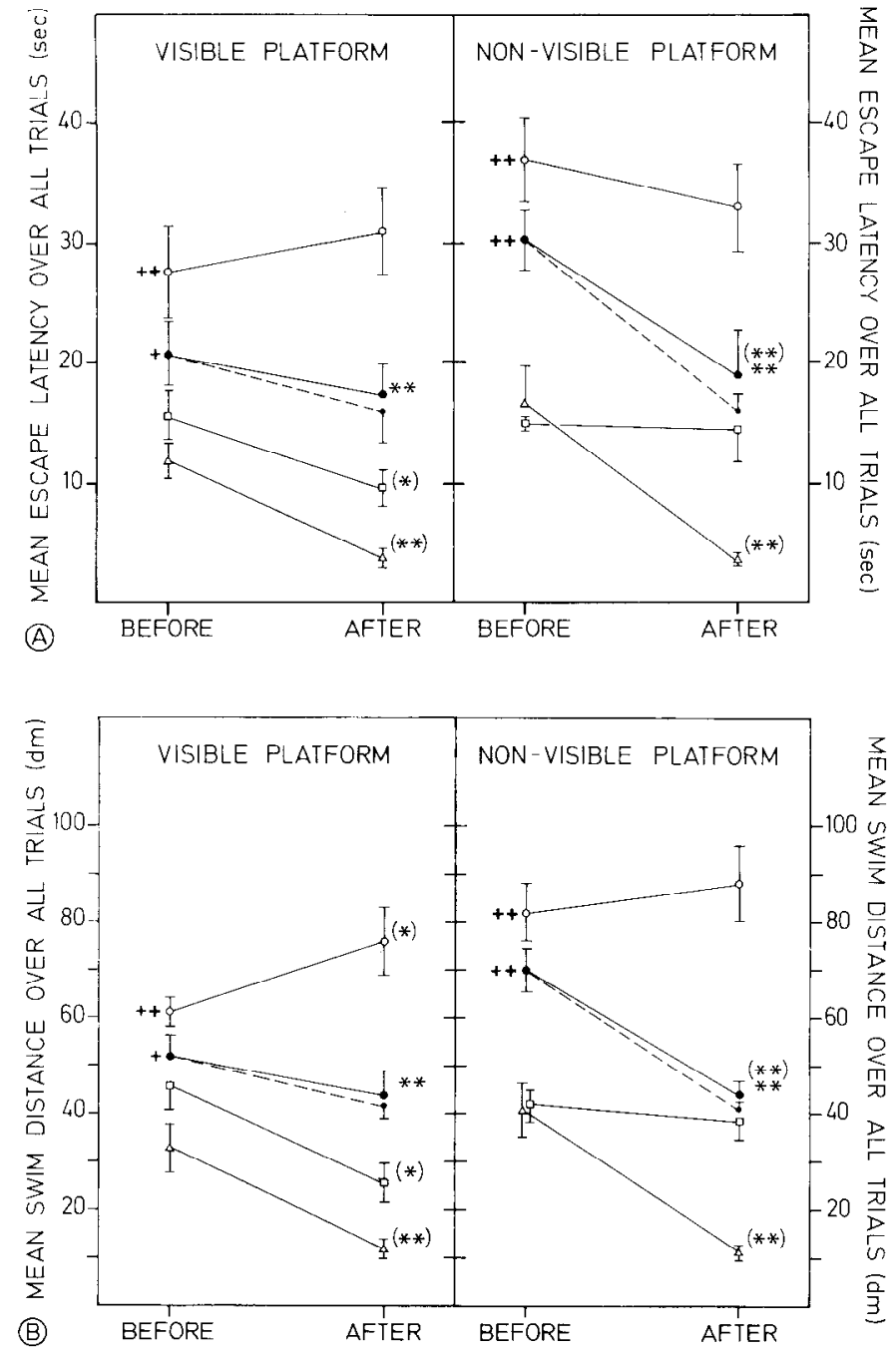

Figure 3. Acquisition of the water-maze task in the pre- and posttransplantation test. $A$, Comparison between mean escape latency (in sec) over all trials, before grafting and after grafting, for all groups. $B$, Similar comparison between mean swim distances to reach the platform, expressed in decimeters $(\mathrm{dm})$, over all trials. Performance on cue-navigation is presented in the left panels (visible platform) and performance on place-navigation is presented in the right-hand panels (nonvisible platform). ${ }^{+} p<0.05$ and ${ }^{++} p<0.01$ indicate differences between old impaired and old nonimpaired rats before transplantation; $\left({ }^{*}\right) p<0.05$ and $\left({ }^{* *}\right) p<0.01$ indicate differences between before and after transplantation using paired comparison tests; ${ }^{* *} p<0.01$ indicates differences between the grafted and nongrafted old impaired rats after transplantation. Filled circles and dashed lines indicate the 6 of 7 animals in the grafted group with observed surviving grafts. Symbols: $\triangle$ young $(n=5)$; $\square$ old nonimpaired $(n=5)$; O old impaired controls $(n=6)$; old impaired grafted $(n=7)$.

with visible and nonvisible platform ( $p$ at least $<0.05$; 1-way ANOVA with post hoc Newman-Keuls test), but the 2 old impaired groups did not differ from each other. These effects were seen both when the acquisition was measured as the time to find the platform (Fig. $3 A$ ) and when it was expressed as the distance of the path swum to reach the platform (Fig. $3 B$ ). In no instance was the old nonimpaired group different from the young control group in the pretransplant test $(p>0.05)$.

In the place-navigation trials, the grafted rats (like the young controls) were significantly improved in the posttransplant test $(p<0.01$; related $t$ test; filled circles in Fig. 3), whereas neither the old impaired controls (open circles) nor the old nonimpaired 
rats (open squares) showed any improvement between the first and the second test weeks. Moreover, the grafted rats performed significantly better than the nongrafted old impaired controls in the posttransplant test $(p<0.01 ; 1$-way ANOVA with post hoc Newman-Keuls test), and they were improved to the extent that they no longer differed from the nonimpaired old rats. These effects were seen irrespective of whether the acquisition was expressed as escape latency (Fig. $3 A$ ) or as swim distance (Fig. $3 B$ ). In the final microscopic analysis, one of the grafted rats was found to have no surviving graft. This rat was the worst performer of the group and remaincd within the impaircd range (mean escape latency, $41 \mathrm{sec}$ ). The other 6 grafted rats had at least one surviving graft in each hippocampus, and they all reached mean escape latencies in the place-navigation test within the $2 \mathrm{SD}$ limit of the young rats in the pretransplant test. Both the range $(12-20 \mathrm{sec})$ and the mean $(16.0 \mathrm{sec})$ of the escape latencies of these 6 recovered animals with surviving grafts (small filled circles and dashed lines in Figs. 3 and 4) were close to those of the 5 old nonimpaired rats (mean, $15.0 \mathrm{sec}$; range, 13$16 \mathrm{sec}$ ) or to those of the 5 young controls (mean, $16.8 \mathrm{sec}$; range, $11-27 \mathrm{sec}$ ) in the pretransplant test.

In the cue-navigation trials, both the young and the old nonimpaired rats showed significant improvement between the pre- and the posttransplant tests, whereas the nongrafted old impaired rats tended to become worse. This difference was significant ( $p<0.05$; related $t$ test) when the acquisition was measured as swim distance to reach the platform (open circles in Fig. $3 B$ ). The grafted rats showed no significant improvement in cue-navigation between the pre- and the posttransplant tests. In the grafted rats, both the escape latency and the swim distance were maintained at the same level or slightly reduced, and the levels of the nongrafted impaired animals were somewhat increased, to the extent that the grafted group now was significantly better than the nongrafted old impaired group $(p<0.01$ for both escape latency and swim distance; 1-way ANOVA with post hoc Newman-Keuls test). The grafted rats, however, remained as impaired relative to the nonimpaired old rats as in the pretransplant test $(p<0.05)$.

The acquisition curves over the $5 \mathrm{~d}$ of testing in the pre- and posttransplant tests are illustrated for the place-navigation trials in Figure $4 A$, and for the cue-navigation trials in Figure $4 B$. Figure 5 shows the corresponding changes in swim speed over the 2 test sessions.

All 3 groups of rats showed significant acquisition of both tasks during the pretransplant week of testing. While the young and the old nonimpaired rats did not differ from each other, the old impaired rats (filled squares in Fig. 4) took considerably longer to find both the visible and nonvisible platforms. The analysis of the rats' swim speeds in Figure 5 shows that the impaired acquisition in the old impaired group was not simply due to poor swim performance. Thus, the difference in swim speed between the young and the old impaired rats was only marginal (about 10-20\%) throughout the test week, and it reached significance only in the place-navigation trials $(p<0.05 ; 2$-way ANOVA).

In the posttransplant test, performed 12 weeks after grafting and 14-17 weeks after the first test, the young rats and the grafted old impaired rats clearly retained the performance level they had reached by the end of the pretransplant test week, and both groups tended to improve their performance somewhat during the second week (triangles and filled circles, respectively, in the right-hand panels in Fig. 4). By contrast, the nongrafted old impaired rats performed significantly worse in both tests during the sccond wcck than by the cnd of the first test wcck, and they did not show any improvement over the second test week. There was a (nonsignificant) tendency in the same direction in the old nonimpaired group, but only in the place-navigation task.

These effects on the retention of the place-navigational and
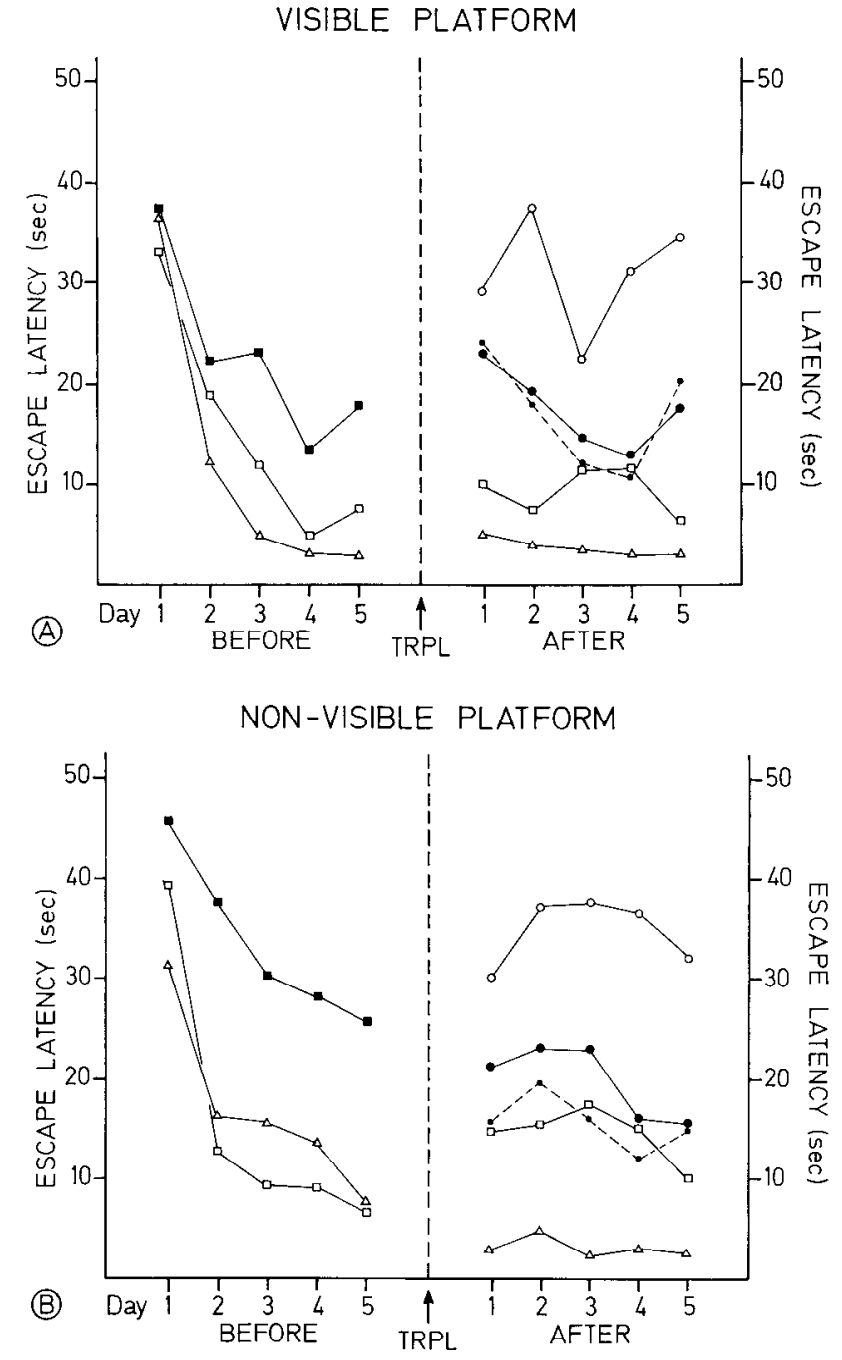

Figure 4. Acquisition of the water-maze task, expressed as the mean escape latency (in sec) for each day of testing before and after transplantation (TRPL) during $(A)$ cue-navigation (visible platform) and $(B)$ place-navigation (nonvisible platform). Filled circles and dashed lines indicate the 6 of 7 animals in the grafted group with observed surviving grafts. Symbols: $\triangle$ young $(n=5) ; \square$ old nonimpaired $(n=5) ; 0$ old impaired controls $(n=6)$; old impaired grafted $(n=7)$; $\boldsymbol{\square}$ old impaired: combined pretransplant test $(n=13)$.

cue-navigational skills acquired during the first test week is illustrated in Figure 6, where the performance during the last 2 $\mathrm{d}$ of testing in the pretransplant test is compared with the performance during the first $2 \mathrm{~d}$ of the posttransplant test. The nongrafted old impaired rats (open circles) showed a highly significant retention deficit on both tasks. This was most pronounced when the performance was expressed as the distance of the swim path to find the platform $(p<0.01$; related $t$ test), which reflects the fact that they swam faster in the beginning of the second test week than during the first week (Fig. 5). The grafted rats (filled circles in Fig. 6) showed significantly better retention, particularly of the place-navigation task and, when measured as swim distance to find the platform (right-hand panel in Fig. 6), the grafted animals were significantly better than the old impaircd controls as early as the first $2 \mathrm{~d}$ of the posttransplant test ( $p<0.05$; unrelated $t$ test).

The swim speed in the posttransplant test (right-hand panels in Fig. 5) was 20-30\% lower overall in all aged groups compared to the young controls ( $p<0.01 ; 2$-way ANOVA). This differ- 

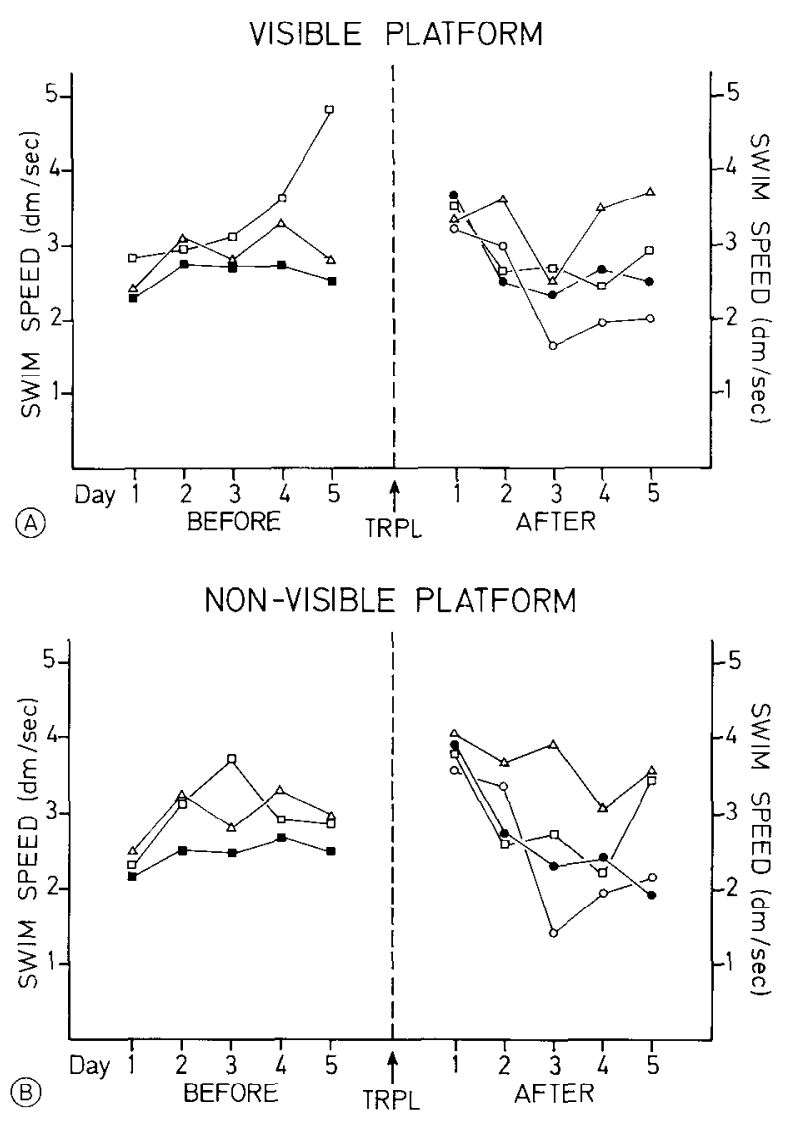

Figure 5. Motor performance: Swim speed (in $\mathrm{dm} / \mathrm{sec}$ ) expressed as the mean for each day of testing before and after transplantation during $(A)$ cue-navigation (visible platform) and $(B)$ place-navigation (nonvisible platform). Symbols for groups are the same as in Figure 4.

ence was largely due to an increase in swim speed in the young control group between the first and the second test (from a mean of $2.9 \mathrm{dm} / \mathrm{sec}$ in the pretransplant test, to a mean of $3.4-3.6$ $\mathrm{dm} / \mathrm{sec}$ in the posttransplant test). The 3 aged groups did not differ from each other, which indicates that the graft effects on the performance of the aged rats in the water-maze were not due to any more nonspecific effects on swimming abilities, or on the motivation to swim, in the grafted rats.

\section{Comparison between place- and cue-navigational performance in the grafted rats}

In the pretransplant test, the old impaired rats performed significantly better in the cue-navigation than on the place-navigation trials (Fig. $2 ; p<0.01$; related $t$ test). This was evident both when acquisition was measured as escape latency (Fig. 3A) and swim distance to find the platform (Fig. $3 B$ ). As seen in Figure 4 (left-hand panels), the old impaired rats (like the young controls) acquired the task faster when the platform was visible, and they reached 30-50\% shorter escape latencies by the end of the $5 \mathrm{~d}$ test period. In the posttransplant test, the grafted rats had significantly improved their performance in the place-navigation task but not in the cue-navigation task (asterisks within brackets in Fig. 3). As a result, the grafted animals performed equally well on both tasks in the posttransplant test (filled circles in Fig. 3 and right-hand panels in Fig. 4). The nongrafted old impaired rats had apparently deteriorated further between the first and the second test, and they were now equally bad in the place- and the cue-navigation trials (open circles in Figs. 3 and 4). This was in contrast to the rats in the old nonimpaired group, which performed significantly better in the cue-navigation task

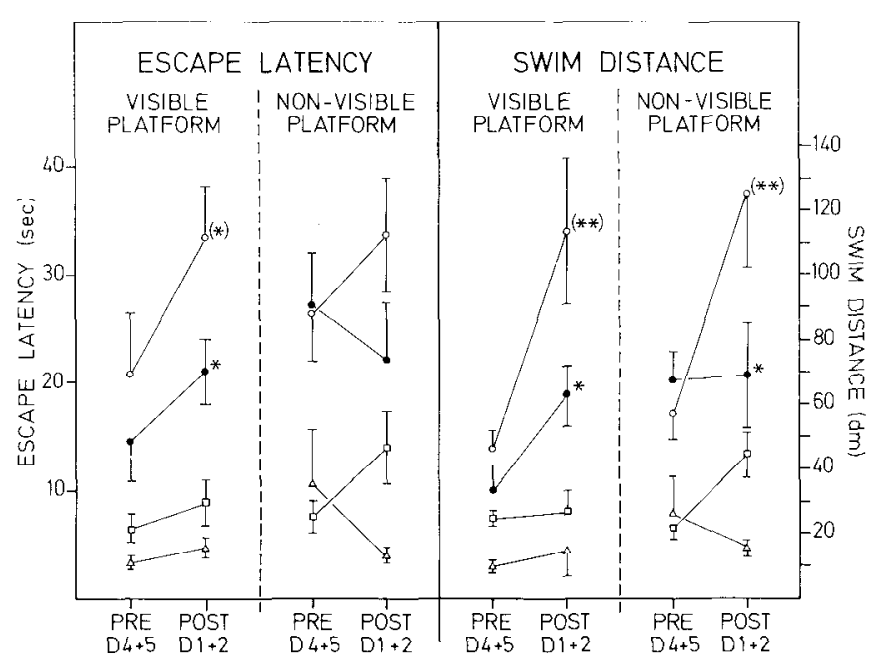

Figure 6. Retention test: Comparison between days 4 and 5 pretransplantation and days 1 and 2 posttransplantation for each group on both cue-navigation (visible platform) and place (nonvisible platform). Mean escape latency in left panels, and swim distance to reach the platform in the right panel. ${ }^{*} p<0.05$ indicates differences between grafted and nongrafted old impaired rats posttransplantation. $\left({ }^{*}\right) p<0.05$ and $\left.{ }^{* *}\right) p<0.01$ indicate differences between the pre- and the posttransplantation tests. Symbols: $O$ old impaired controls; - old impaired grafted; $\square$ old nonimpaired; $\triangle$ young controls.

(about 30\% shorter mean escape latencies; $p<0.05$, related $t$ tcst) in the posttransplant test.

Accuracy of platform localization in the "spatial probe" test The ability of the rats to use spatial cues for the localization of the platform in the pool was assessed by analyzing their search behavior after removal of the platform on the final day of testing. In Figure 7 the focus of the search over the previous platform site has been expressed both as the number of crossings over the platform site and the percentage of the total swim path located within the platform quadrant of the pool. While the nongrafted old impaired rats remained severely impaired on these measures ( $p<0.01$ compared to both young and old nonimpaired groups; 1-way ANOVA with post hoc Newman-Keuls test), the grafted rats showed significantly improved performance using both measures compared to the nongrafted controls $(p<0.01$; black columns in Fig. 7). The grafted rats were no longer different from the old nonimpaired rats $(p<0.05$ on both measures). They remained impaired relative to the young rats, however, on the measure of number of crossings over the platform site $(p<0.01)$. These effects are illustrated in Figure 10 by the actual swim paths of the median rat (according to the performance in the posttransplant test) in each of the 4 groups.

In Figure 11 (open columns) the search behavior after platform removal is expressed as the total swim distance over the 2 min observation period (left panel) and the number of times the rats swam through the central area of any of the 4 quadrants in the pool (i.e., the 4 potential platform locations, so-called annulus crossing; see inset figure in the right-hand panel). The old impaired rats were severely impaired also on these measures $(p<0.01)$. The grafted rats searched significantly more actively over the 4 potential platform locations than the old impaired controls $(p<0.05)$. They were not significantly different from the nonimpaired old rats, but they searched less than the young control rats $(p<0.05)$. Interestingly, if the shorter search distance by the grafted rats is taken into account, the precision in platform localization (as reflected in the platform crossings measure in Fig. 7) is similar in the young, the old nonimpaired, and the grafted rats. Thus, the average number of crossings over the 


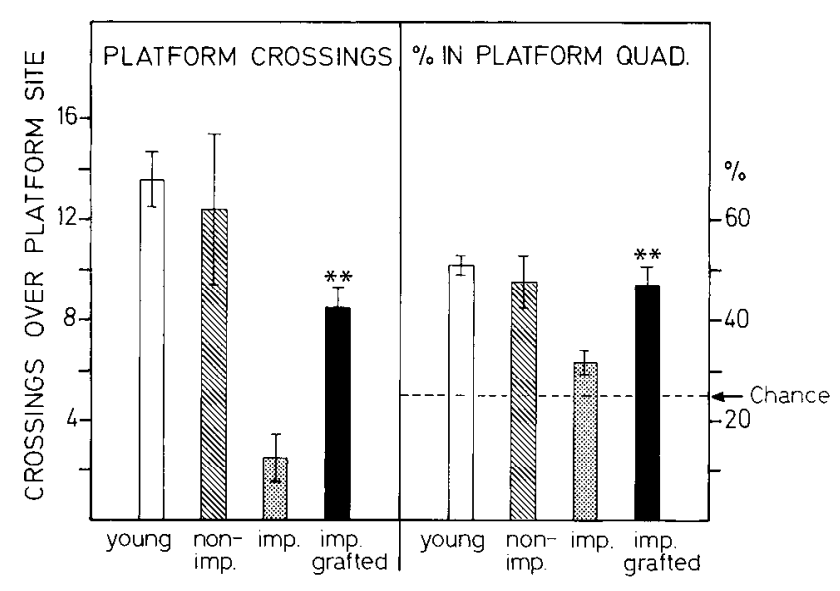

Figure 7. "Spatial probe" test posttransplantation. Left, Number of crossings over the location where the platform had been during all previous trials. Right, Percentage of total swim distance in the quadrant of the pool where the platform had been during all previous trials. imp, Impaired. ${ }^{* *} p<0.01$ indicates differences between old-impaired controls and old-impaired grafted animals. Dashed line indicates the chance performance level $(=25 \%)$.

previous platform sitc per metcr distance was 0.27 in the young, 0.33 in the nonimpaired old, and 0.24 in the grafted rats, but only 0.06 in the nongrafted old impaired controls.

\section{Effects of atropine and physostigmine on the water-maze} performance in the aged and grafted rats

The effects of physostigmine $(0.05 \mathrm{mg} / \mathrm{kg})$, atropine $(50 \mathrm{mg} / \mathrm{kg})$, or saline were tested during 4 consecutive days (Fig. 8). The rats received 8 trials each day in the water-maze, with alternating visible and nonvisible platform, followed by one "spatial probe" test when the platform was removed. The drug (or saline) was given 15 min prior to the first trial.

Physostigmine was without effect in the young or the old nonimpaired rats (top panels in Fig. 8), whereas the nongrafted old impaired rats were significantly improved in cue-navigation alone $(p<0.05$ compared to either no drug, day 1 , or saline, day 3 ; related $t$ test). The same tendency was seen for cuenavigation in the grafted old impaired rats (lower panel in Fig. 8 ), but it did not reach statistical significance. Nevertheless, under physostigmine the grafted rats performed significantly better than the nongrafted old impaired rats in both the cueand the place-navigation trials $(p<0.05 ; 1$-way ANOVA with post hoc Newman-Keuls test). Physostigmine had no significant effects on platform localization in the "spatial probe" trial in any of the groups.

Atropine, given prior to testing on day 4 , was without effect in the young rats, but produced a dramatic impairment both in the cue- and place-navigation trials in the old nonimpaired rats and in the grafted animals ( $p<0.001$ for both groups compared to saline on day 3 ; paired $t$ test). Under atropine the nongrafted old impaired rats also tended to be further impaired (although this did not reach statistical significance), and the differences between grafted and nongrafted old impaired rats, and between the old impaired and nonimpaired rats, were totally abolished.

As shown in Figure 9, atropine also abolished the aged rats' ability to localize the platform site after platform removal, while the young rats were only marginally affected. Thus, both the nonimpaired aged rats and the grafted rats appeared to be significantly more sensitive to atropine than the young controls in this respect. Under atropine the grafted rats, as well as the nonimpaired aged rats, were just as impaired as the nongrafted old impaired ones, and all 3 groups performed no better than chance.

Further analysis of the rats' swim paths, as illustrated for
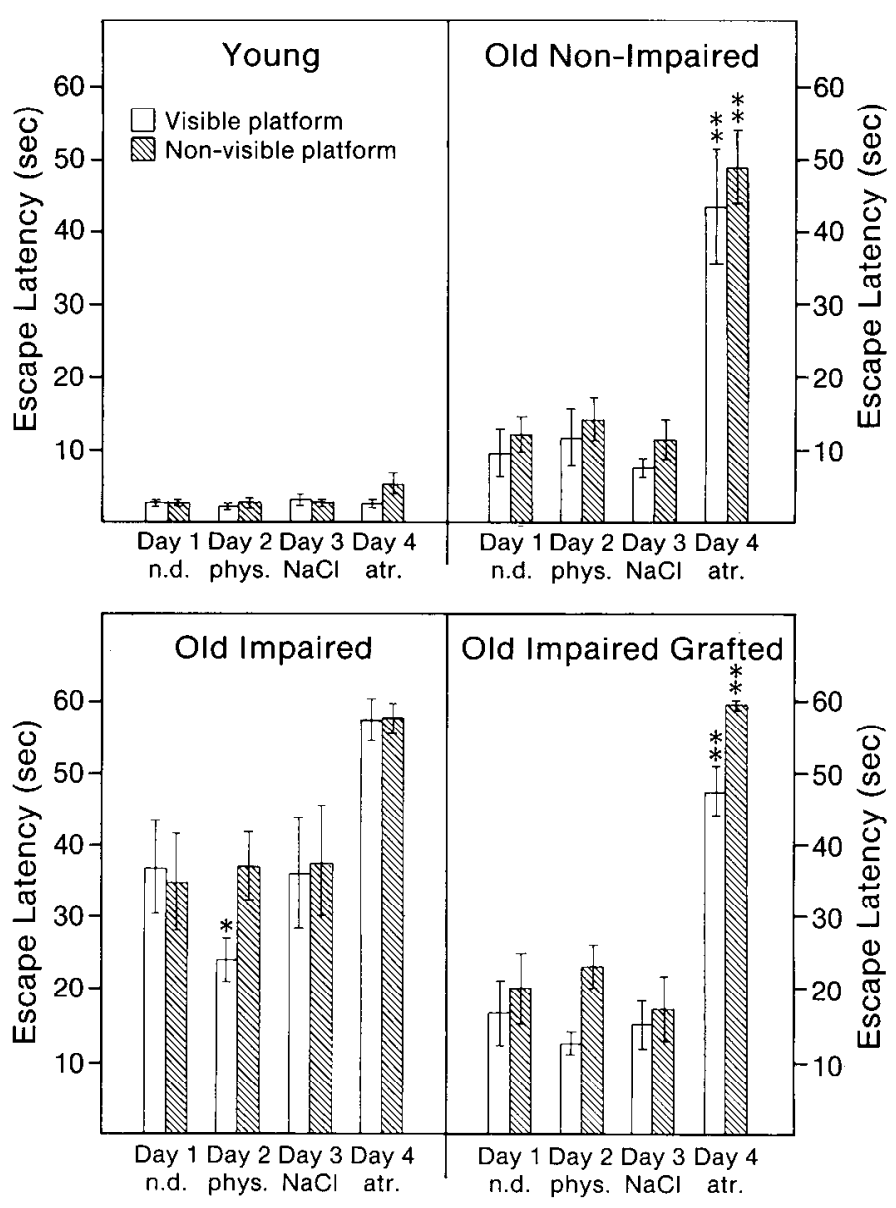

Figure 8. Drug tests: Mean escape latencies for each group on the 4 consecutive days of drug testing for cue- (visible platform) and place(nonvisible platform) navigation in the grafted and nongrafted animal groups. n.d., No drug; phys, physostigmine $(0.01 \mathrm{mg} / \mathrm{kg}) ; \mathrm{NaCl}$, saline $(0.9 \%)$; atr, atropine sulfate $(50 \mathrm{mg} / \mathrm{kg})$. Drugs were given $15 \mathrm{~min}$ before the first trial.

individual rats in Figure 10, showed that the atropine-treated aged rats lacked any efficient search strategy (spatial or nonspatial) that may have helped them to find the platform. They swam predominantly along the perimeter of the pool, with no or only occasional crossings over the interior of the pool, a pattern that is otherwise typical for a rat that has never been in the pool before. In the young controls, the only effect of the atropine pretreatment was a tendency to swim in larger loops while retaining the same number of crossings over the previous platform site. In Figure 11, the general search behavior after platform removal is expressed as total search distance (left panel) and the number of times the rats swam through the central area of each of the 4 quadrants (so-called annulus crossings; right-hand panel). Without drug treatment, the rats in the grafted and nonimpaired aged groups had significantly higher annulus crossing scores than the rats in the impaired nongrafted aged group (open columns). This performance was, however, totally abolished in all 3 aged groups (filled columns). On the total search distance measure, all aged rats tended to be further impaired under atropine, but the differences between the groups were retained. By contrast, the young controls were unaffected by atropine on both measures.

The analysis of the rats' swim speed (Fig. 12) showed that there were no effects on the swimming abilities in any of the groups under physostigmine or atropine. This indicates that the effects of the 2 drugs on escape latency in Figure 8 were not 

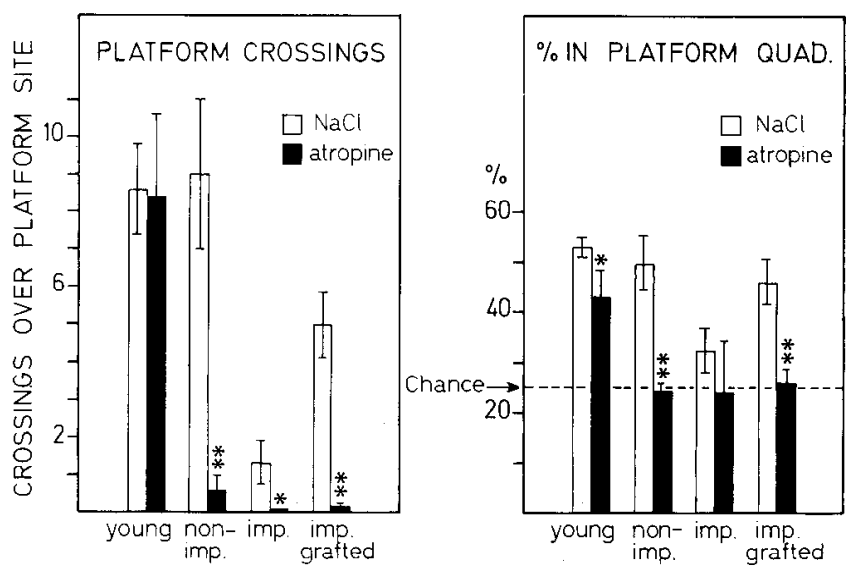

Figure 9. Drug effects on the performance in the "spatial probe" test. $L e f t$, Effect of atropinc on the total number of crossings over the location where the platform had been on all previous trials. Right, Effect of atropine on the percentage of the total swim distance in the quadrant where the platform had been on all previous trials. $i m p=$ impaired. ${ }^{*} p<0.05$ and ${ }^{* *} p<0.01$ indicate differences between saline and atropine test days. Dashed line gives the chance performance level.

confounded by any nonspecific effects of the drugs on the rats' motor performance in the pool.

\section{Discussion}

\section{Features of the water-maze deficits in the aged rats}

Experimental studies in young rats have shown that muscarinic cholinergic blockade induced by systemic administration of atropine causes a substantial impairment in acquisition of placenavigation, but not cue-navigation, in the water-maze task but that the retention of already learned place-navigation is only marginally affected (Sutherland et al., 1982a; Wishaw, 1985; Wishaw et al., 1985). Excitotoxic lesion of the nucleus basalis, which removes the cholinergic projection to the frontoparietal cortex (Wishaw et al., 1985), or transection of the fimbria-fornix, which removes the cholinergic afferents to the hippocampal formation (Nilsson et al., 1985), both have an effect similar to atropine on the acquisition of place-navigation. While the nucleus basalis lesion, like atropine, causes only mild retention impairments (Wishaw et al., 1985), the fimbria-fornix transection has been found to impair place-navigation in pretrained animals also, although they are able to relearn the task partially with a nonspatial strategy (Nilsson et al., 1985). Similar deficits are also seen after frontal cortical or hippocampal ablations (Sutherland et al., 1982b, 1983; Morris et al., 1982).

This suggests that the functional integrity of the hippocampalprefrontal circuitries is essential for place-navigation in the rat and that the cholinergic projection systems exert some enabling function on these target areas. Navigation using nonspatial sirategies in the water-maze is spared after manipulations of the cholinergic projection systems and can apparently be affected by cortical or hippocampal ablations only if they are combined with subcortical lesions (Wishaw and Kolb, 1984) or by damage to brain-stem regulatory systems, such as the mesotelencephalic dopamine pathway (Wishaw et al., 1985).

The impaired old rats (which constituted about $40 \%$ of the total 2-year-old population in the present study and about $30 \%$ of the total population in our previous study; Gage et al., 1984a) are clearly more impaircd on the place-navigation task than either atropine-treated or nucleus basalis-lesioned young rats (Sutherland et al., 1982a; Wishaw, 1985; Wishaw et al., 1985), and at least as impaired as young rats with fimbria-fornix lesions or hippocampal or frontal cortex ablations (Gage et al., 1983;
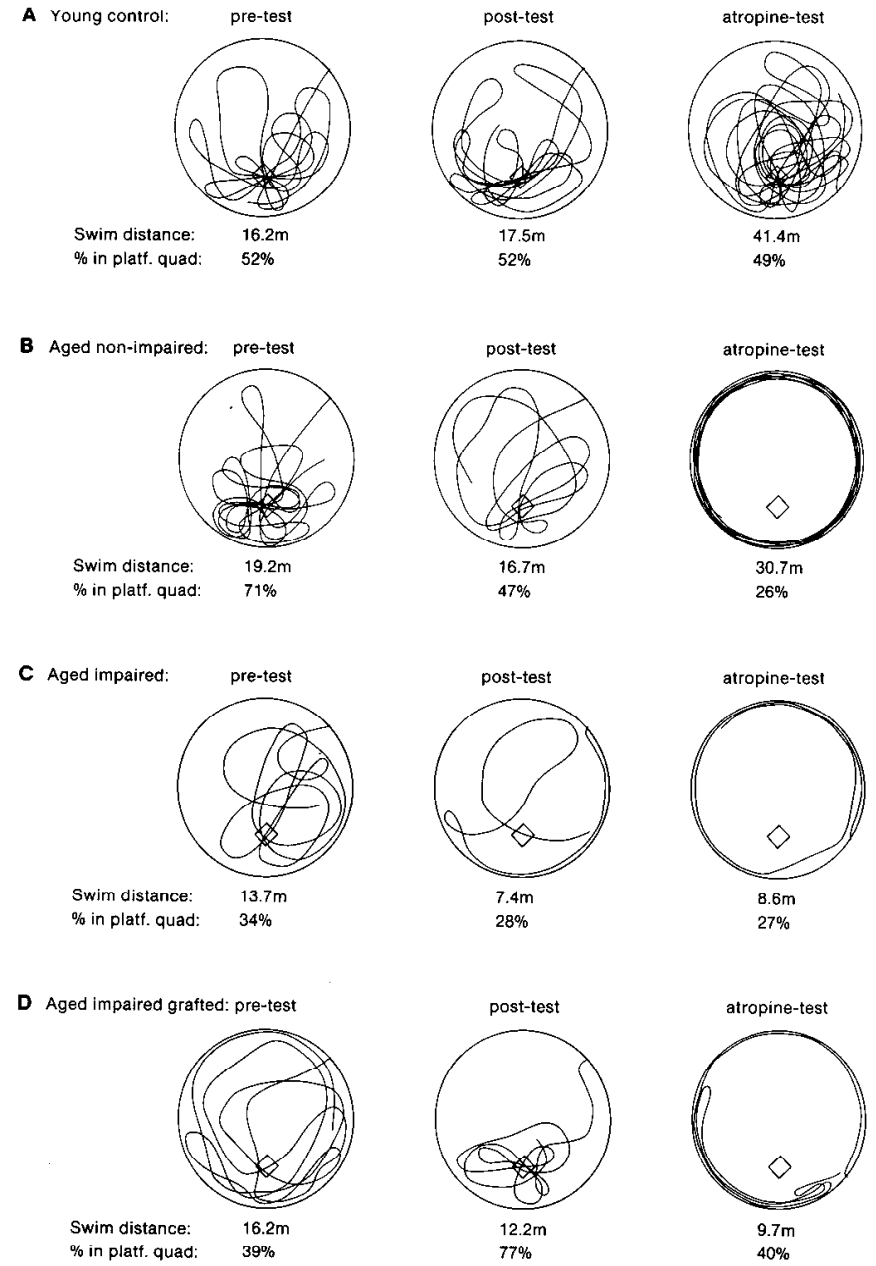

Figure 10. Swim patterns in the "spatial probe" test: Direct tracings of the search behavior after platform removal of a young control rat $(A)$, an old nonimpaired rat $(B)$, an old impaired control rat $(C)$, and an old impaired grafted rat $(D)$. Left panel gives the performance in the last trial of the pretransplant test, middle panel gives the performance in the last trial of the posttransplant test, and right panel shows the performance under atropine. The rats represented were selected as having median performances in each group. The length of the swim path (in $\mathrm{m}$ ) and the percentage of the total distance located within the platform quadrant are given below each test result.

Morris et al., 1982; Sutherland et al., 1982b). Thus, in our previous study, where the rats were trained only with a hidden platform, the old impaired rats showed no reduction at all in escape latency over the 2 weeks of training. In the present study we chose, therefore, to introduce alternating cue-navigation trials, in which the platform was clearly visible from the water surface. Since the rats should be able to find the visible platform without the use of any spatial memory based on extra-maze cues, the alternating cue-navigation trials should reveal whether the old impaired rats, in the absence of any effective spatial mapping strategies, would be able to adopt a cue-learning strategy in order to find the platform. The results indicate that this indeed is the case: The old impaired rats showed a significant reduction in latency over the first test week (interestingly both in the cuenavigation and the place-navigation trials), and they were significantly better in finding the platform when it was visible than when it was not. Even with this simplified procedure, however, the old impaired rats remained as impaired by the end of the test week as rats subjected to, for example, chronic atropine treatment (Wishaw, 1985) or bilateral hippocampal ablation 


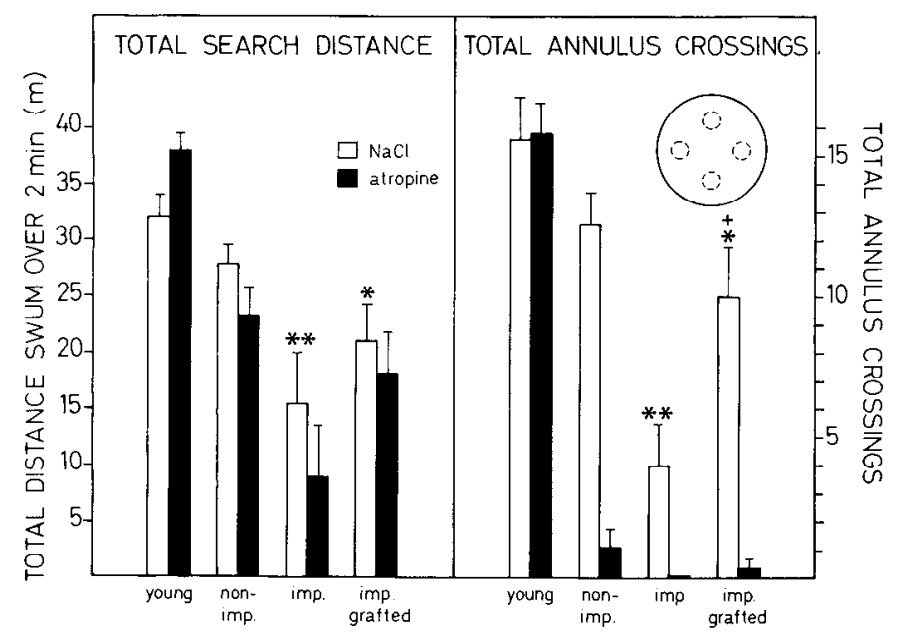

Figure 11. Search performance and platform removal. Left, Total distance swum over 2 min (in $\mathrm{m}$ ) in the "spatial probe" trial, following saline or atropine injections. Right, Total number of crossings in any of the 4 annuli (see inset) corresponding to the 4 potential platform sites in the center of each of the 4 quadrants in the pool. imp. Impaired. $*_{p}<0.01$ indicates differences from young control rats in the saline test; ${ }^{+} p<0.05$ indicates difference between the grafted and nongrafted old impaired rats.

(Morris et al., 1982). Moreover, the old impaired rats deteriorated further over the 12 week period separating the pre- and the posttransplant tests. They lost the acquisition level they had reached during the first test week on both tasks; they did not show any further acquisition over the second test week; and there was no longer any difference in performance of the rats between visible and nonvisible platform trials. Thus, at this stage the old impaired rats seemed incapable of any type of search strategy (spatial or nonspatial) to find the platform. This observation, by itself, makes it highly unlikely that the learning impairments in the old impaired rats are due solely to a cholinergic deficit.

Over the 12 weeks separating the 2 tests, the nonimpaired old rats also tended to deteriorate to the extent that they were significantly impaired compared to the young controls in the placenavigation trials in the posttransplant test, and they did not show any further reduction in escape latency over the second test week. Nevertheless, their performance was still much superior to that of the rats in the old impaired group, and their localization of the platform site in the "spatial probe" test after platform removal was as good as that of the young controls. However, in contrast to the young control rats, which showed only mild place-navigational retention impairments under atropine, the rats in the nonimpaired old group were dramatically impaired after atropine treatment, and their ability to localize the platform site after platform removal was completely eliminated. The drug effect was similar in both the place-navigation and the cue-navigation trials, which suggests that, with the present alternating visible-nonvisible platform design, the rats adopted similar spatial navigational strategies regardless of whether the platform was visible or nol, and that the visible platform was used as a local cue only when the rat was approaching the platform site.

The intriguing difference in atropine sensitivity between the rats in the young and the old nonimpaired groups may be explained in several different ways. One possibility is that the cholinergic system in the old rats might be more vulnerable to muscarinic receptor blockade than it is in young animals. This would be in agreement with reports of reduced muscarinic receptor binding and ACh synthesis rates in hippocampal and
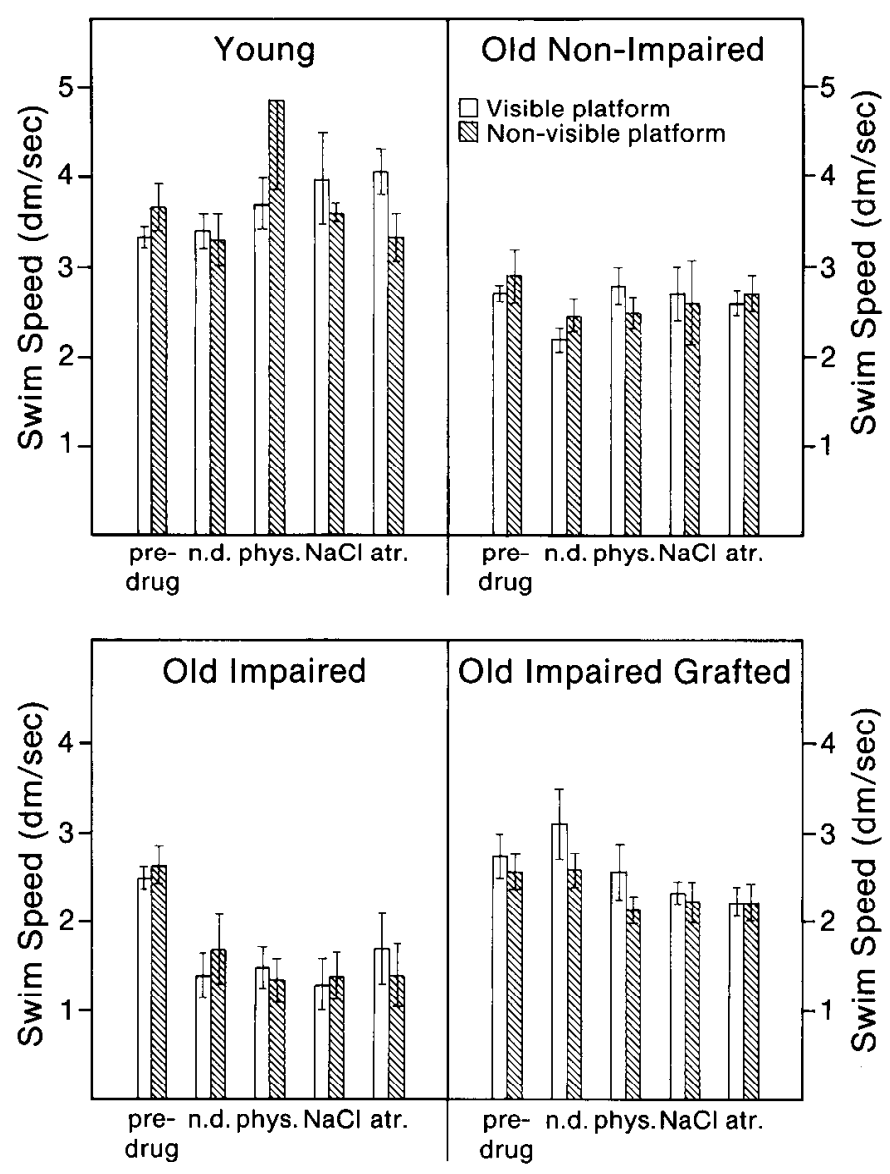

Figure 12. Motor performance during drug tests: Mean swim speed (expressed in $\mathrm{dm} / \mathrm{sec}$ ) for each group for cue- (visible platform) and place- (nonvisible platform) navigation. n.d., No drug; phys, physostigmine $(0.01 \mathrm{mg} / \mathrm{kg}) ; \mathrm{NaCl}$, saline $(0.9 \%)$; atr, atropine sulfate $(50 \mathrm{mg})$ $\mathrm{kg}$ ).

cortical areas in aged rats (Lippa et al., 1980, 1981; Sherman et al., 1981; Sims et al., 1982). This interpretation also seems consistent with the observation that physostigmine treatment produced a small but significant improvement in performance in the aged impaired rats.

An alternative way to explain the differential atropine sensitivity in young and aged rats is in terms of a selective defect in atropine-resistant place-learning in the aged animals. Young rats are sensitive to atropine only during early stages of training in the water-maze. Wishaw (1985) has described this as a transition from atropine-sensitive place-learning (analogous to rapid acquisition memory processes like working memory) to an atropine-resistant place-learning, which may depend largely on welltrained cue- and position-response strategies. Viewed in this way, the atropine-sensitivity of the rats in the old nonimpaired group may signify that they are defective in the mechanism underlying atropine-resistant place learning or slower in aquisition of such learning, and thus that the old rats remain dependent on the atropine-sensitive (probably cholinergic) place-learning mechanism even after a relatively long training when they seemed to have reached asymptotic performance. This suggests that the cholinergic forebrain system is still functional in the old nonimpaired rats. Since Wishaw (1985) reports that the atropineresistant place-learning mechanism can be interfered with only by anatomically extensive lesions, such as complete hippocampal ablations or decortication, the deficit underlying the atropine-sensitivity of the old rats may reflect an anatomically more diffuse limbic system or cortical damage, which is known to 
occur in aged rats (Landfield et al., 1977, 1981; Sabel and Stein, 1981)

It is interesting to note that the rats in the nonimpaired aged group (which in the absence of any drug treatment performed the water-maze task very well) performed under atropine just as badly as the old impaired rats, whereas the performance of the old impaired rats was hardly affected by atropine. Following the same reasoning as above, this may be taken to indicate that the principal difference between the impaired and nonimpaired groups of aged rats is in the functional integrity of the cholinergic system. We hypothesize, therefore, that the noncholinergic and anatomically probably more diffuse deficits (underlying, e.g., atropine-resistant place navigation, see above) are relatively uniformly distributed over the present aged rat population and that the difference in place-navigational performance between the 2 aged rat populations in the water-maze task is critically dependent on the functional integrity of the forebrain cholinergic projection system, or certain parts of this system. The results obtained in the septal grafted animals seem to provide further support for this idea.

\section{Characteristics of the graft-induced effects}

The principal graft-induced effects observed in the old impaired rats can be summarized as follows:

1. The grafted rats performed significantly better than the nongrafted old impaired controls on the posttransplant test. They were improved up to the performance level of the nonimpaired aged rats but remained impaired relative to the young controls. These effects were independent of any more nonspecific motor effects on the swimming abilities of the aged rats in the pool.

2 . The grafted rats showed a significant overall improvement between the pre- and the posttransplant tests, while the nongrafted rats in the old impaired control group tended to be further impaired in the second test. The grafts thus seemed both to improve performance in the second, posttransplant, test and to prevent further behavioral deterioration in the aged animals between the 2 tests.

3. The grafts improved retention of the acquired performance level over the 12-week period separating the pre- and the posttransplant tests. Whilc the old impaired controls performed significantly worse in the beginning of the second test as compared to the end of the first test, the grafted rats (similar to the young controls) retained their performance level.

4. The grafted rats did not improve their performance in the water-maze navigation task when the platform was visible, which indicates that the grafted animals had adopted a largely spatialnavigation strategy, using extra-maze cues, also in the cued trials. However, other age-related changes could also contribute to this lack of improvement.

5. In the "spatial probe" test, the rats' ability to use distant spatial cues for the location of the platform site in the pool was assessed by analyzing their search behavior after removal of the platform. While the nongrafted old impaired controls remained severely impaired on this measure after the posttransplant test, the grafted rats recovered dramatically. They focused their search on the platform quadrant of the pool to the same degree as the rats in young and nonimpaired aged groups. The number of platform crossings was significantly lower in the grafted rats than in the young controls (but not significantly different from the old impaired rats). This seemed, however, to reflect a less active search behavior in the grafted rats rather than a poorer precision of their spatial memory. Thus, the lower number of platform crossings in the grafted rats versus the young controls in the "spatial probe" trial was entirely accounted for by their shorter search distance, a factor that is more likely to depend on general motor weakness or fatigue than cognitive disability.

6 . The recovered navigational ability in the grafted animals was completely abolished after administration of the muscarinic antagonist atropine, and this was also the case for the recovered spatial memory (i.e., the ability to locate the previous platform site by means of distal cues) in the "spatial probe" test. Thus, the grafted animals showed the same difference in atropinesensitivity compared to the young well-trained control rats as the nonimpaired aged controls (cf. above). Physostigmine, given over a single day of testing, had no significant effect.

The combined evidence from the present and our previous study (Gage et al., 1984a) indicates that the graft-induced improvement in water-maze performance in the aged rats is due primarily to a recovery in the ability of the grafted rats to use spatial cues in the localization of either visible or nonvisible escape platforms in the pool. The data indicate that the grafts had an effect both on the retention of the performance level (measured as distance or time to find the platform) acquired in the test performed prior to the transplantation surgery and on the acquisition of spatial memory of the platform site during the posttransplant test week (measured as an improved focusing of search over the platform site in the "spatial probe" test). Other aspects of the performance deficits of the aged rats in the water-maze test were, however, unaffected by the grafts. This was particularly evident in the so-called atropine-resistant placelearning (Wishaw, 1985). Thus, similar to the aged (impaired or nonimpaired) control rats, the grafted rats were incapable of any efficient search behavior after atropine treatment. As discussed above, this may reflect: (1) impaired cholinergic transmission in other forebrain regions unaffected by the intrahippocampal grafts; (2) postsynaptic deficits, such as loss of muscarinic receptors on target neurons, which also make the graft function more sensitive to cholinergic receptor blockade; or (3) noncholinergic and anatomically more diffuse neuronal damage that is left unaffected by the septal grafts.

The atropine sensitivity of the graft-induced recovered behavior provides evidence that the function of the septal grafts is dependent on a cholinergic mechanism. Cytochemical studies in aged rats with intrahippocampal septal grafts have shown that the cholinergic (AChE-positive and choline acetyltransferase-positive) neurons in the graft are capable of establishing a new terminal network in areas of the host hippocampus and dentate gyrus (Clarke et al., 1985b; Gage et al., 1983, 1984a), and that these graft-derived cholinergic terminals form extensive synaptic contacts with neuronal elements in the hippocampal formation (Clarke et al., 1985b). Thus, the combined morphological and pharmacological data provide strong support for the idea that the ability of the septal grafts to ameliorate the spatial learning impairments in aged rats is critically dependent on the cholinergic neurons in the grafts, and, moreover, that the cholinergic effect is mediated through a direct action on neuronal elements in the hippocampal formation via synapses established by their ingrowing axons. This is in line also with the interpretation of the functional effects of grafted septal neurons in young rats with lesions of the fimbria-fornix (Dunnett et al., 1982; Kelly et al., 1985; Low et al., 1983; Segal et al., 1985), where the functional recovery has been found to be significantly correlated with the degree of cholinergic fiber ingrowth into the host hippocampal formation. However, neither in grafted lesioned young rats (Dunnett et al., 1982) nor in grafted aged rats (Gage et al., 1984a) is this correlation perfect: our impression is that cholinergic fiber ingrowth is a necessary requirement for the functional effects to occur, but that this may not be the sole critical factor in the observed graft effects. What these other factors may be is presently a matter of speculation. It seems possible that other types of neurons in the graft can be necessary or that specific afferent graft connections have to be established from the host in order for the cholinergic neurons to function correctly. Until these possibilities are tested, it remains conceivable that the effects of the grafts on this behavior are not dependent on connectivity and that diffuse transmitter release may be sufficient to account for at least some functional recov- 
ery. Furthermore, it remains a possibility that this potential diffuse release of transmitter from the graft could be affecting some nonhippocampal structures in addition to the hippocampus to induce the observed recovery. Future studies will be directed at determining the necessity and specificity of hostgraft and graft-host connectivity for the observed recovery.

\section{References}

Bartus, R. T., R. L. Dean, B. Beer, and A. S. Lippa (1982) The cholinergic hypothesis of geriatric memory dysfunction. Science 217: 408-416.

Björklund, A., and U. Stenevi (1977) Reformation of the severed septohippocampal cholinergic pathway in the adult rat by transplanted septal neurones. Cell Tissue Res. 185: 289-302.

Björklund, A., F. H. Gage, U. Stenevi, and S. B. Dunnett (1983a) Intracerebral grafting of neuronal cell suspensions. VI. Survival and growth of intrahippocampal implants of septal cell suspensions. Acta Physiol. Scand. Suppl. 522: 49-58.

Björklund, A., F. H. Gage, R. H. Schmidt, U. Stenevi, and S. B. Dunnett (1983b) Intracerebral grafting of neuronal cell suspensions. VII. Recovery of choline acetyltransferase activity and acetylcholine synthesis in the denervated hippocampus reinnervated by septal suspension implants. Acta Physiol. Scand. [Suppl.] 522: 59-66.

Björklund, A., U. Stenevi, R. H. Schmidt, S. B. Dunnett, and F. H. Gage (1983c) Intracerebral grafting of neuronal cell suspensions: I. Introduction and general methods of preparation. Acta Physiol. Scand. [Suppl.] 522: 1-7.

Clarke, D. J., F. H. Gage, and A. Björklund (1985a) Formation of cholinergic synapses in the dentate gyrus of behaviorally-impaired young and aged rats by grafted basal forebrain neurons. Soc. Neurosci. Abstr.

Clarke, D. J., F. H. Gage, and A. Björklund (1985b) Formation of cholinergic synapses by intra-hippocampal septal grafts as revealed by choline acetyl-transferase immunocytochemistry. Brain Res. 369: $151-162$.

Coyle, J. T., D. L. Price, and M. R. DeLong (1983) Alzheimer's disease: A disorder of cortical cholinergic innervation. Science 219: 11841189.

Dunnett, S. B., W. C. Low, S. D. Iversen, U. Stenevi, and A. Björklund (1982) Septal transplants restore maze learning in rats with fimbriafornix lesions. Brain Res. 251: 335-348.

Dunnett, S. B., G. Toniolo, A. Fine, C. N. Ryan, A. Björklund, and S. D. Iversen (1985) Transplantation of embryonic ventral forebrain neurons to the neocortex of rats with lesions of nucleus basalis magnocellularis. II. Sensorimotor and learning impairments. Neuroscience 16:787-797.

Fine, A., S. B. Dunnett, A. Björklund, and S. D. Iversen (1985a) Cholinergic ventral forebrain grafts into the neocortex improve passive avoidance memory in a rat model of Alzheimer disease. Proc. Natl. Acad. Sci. USA 82: 5227-5230.

Fine, A., S. B. Dunnett, A. Björklund, D. Clarke, and S. D. Iversen (1985b) Transplantation of embryonic ventral forebrain neurons to the neocortex of rats with lesions of nucleus basalis magnocellularis: I. Biochemical and anatomical observations. Neuroscience 16:769786.

Gage, F. H., S. B. Dunnett, U. Stenevi, and A. Björklund (1983) Intracerebral grafting of neuronal cell suspensions: VIII. Survival and growth implants of nigral and septal cell suspensions in intact brains of aged rats. Acta Physiol. Scand. Suppl. 522: 67-75.

Gage, F. H., A. Björklund, U. Stenevi, S. B. Dunnett, and P. A. T. Kelly (1984a) Intrahippocampal septal grafts ameliorate learning impairments in aged rats. Science 225: 533-536.

Gage, F. H., S. B. Dunnett, and A. Björklund (1984b) Spatial learning and motor deficits in aged rats. Neurobiol. Aging 5: 543-548.

Gage, F. H., P. A. T. Kelly, and A. Björklund (1984c) Regional changes in brain glucose metabolism reflect cognitive impairments in aged rats. J. Neurosci. 1: 2856-2866.

Gibson, G. E., C. Peterson, and D. J. Jenden (1981) Brain acetylcholine synthesis declines with senescence. Science 213: 674-676.

Kelly, P. A. T., F. H. Gage, M. Ingvar, O. Lindvall, U. Stenevi, and A. Björklund (1985) Functional reactivation of the deafferented hippocampus by embryonic septal grafts as assessed by measurements of local glucose utilization. Exp. Brain Res. 58: 570-579.

Kromer, L. F. (1985) Factors in neural transplants which influence regeneration in the mature mammalian central nervous system. In
Neural Grafting in the Mammalian CNS, A. Björklund and U. Stenevi, eds., pp. 309-318, Elsevier, Amsterdam.

Landfield, P. W., G. Rose, L. Sandles, T. C. Wohlstadter, and C. Lynch (1977) Patterns of astroglial hypertrophy and neuronal degeneration in the hippocampus of aged, memory-deficient rats. J. Gerontol. 32: $3-12$.

Landfield, P. W., L. D. Braun, T. A. Pitler, J. D. Lindsey, and G. Lynch (1981) Hippocampal aging in rats: A morphometric study of multiple variables in semithin sections. Neurobiol. Aging 2: 265-275.

Lewis, E. R., and C. W. Cotman (1983) Neurotransmitter characteristics of brain grafts: Striatal and septal tissues form the same laminated input to the hippocampus. Neuroscience 8: 57-66.

Lippa, A. S., R. W. Pelham, B. Beer, D. J. Critchett, R. L. Dean, and R. T. Bartus (1980) Brain cholinergic dysfunction and memory in aged rats. Neurobiol. Aging 1: 13-19.

Lippa, A. S., D. J. Critchett, F. Ehlert, H. I. Yamamura, S. J. Enna, and R. T. Bartus (1981) Age-related alterations in neurotransmitter receptors: An electrophysiological and biochemical analysis. Neurobiol. Aging 2: 3-8.

Low, W. C., P. R. Lewis, and S. T. Bunch (1983) Embryonic neural transplants across a major histocompatibility barrier: Survival and specificity of innervation. Brain Res. 262: 328-333.

Low, W. C., J. K. Daniloff, R. P. Bodony, and J. Wells (1985) Crossspecies transplants of cholinergic neurons and the recovery of function. In Neural Grafting in the Mammalian CNS, A. Björklund and U. Stenevi, eds., pp. 575-584, Llsevier, Amsterdam.

Low, W. C., P. R. Lewis, S. T. Bunch, S. B. Dunnett, S. R. Thomas, S. D. Iversen, A. Björklund, and U. Stenevi (1982) Functional recovery following neural transplantation of embryonic septal nuclei in adult rats with septohippocampal lesions. Nature 300:260-262.

Morris, R. G. M. (1981) Spatial localization does not require the presence of locus cues. Learn. Motiv. 12: 239-260.

Morris, R. G. M. (1984) Developments of a water-maze procedure for studying spatial learning in the rat. J. Neurosci. Methods 11:4760.

Morris, R. G. M., P. Garrud, J. N. P. Rawlins, and J. O'Keefe (1982) Place navigation impaired in rats with hippocampal lesions. Nature 297: 681-683.

Nilsson, O. G., F. H. Gage, and A. Björklund (1985) Cue and place acquisition and performance following fimbria-fornix transection and grafting of basal forebrain cholinergic neurons to the hippocampus. Neurosci. Lett. [Suppl.] 22: S530.

Sabel, B. A., and D. G. Stein (1981) Extensive loss of subcortical neurons in the aging rat brain. Exp. Neurol. 73: 507-516.

Segal, M., A. Björklund, and F. H. Gage (1985) Transplanted septal neurons make viable cholinergic synapses with a host hippocampus. Brain Res. 336: 302-307.

Sherman, K. A., J. E. Kuster, R. L. Dean, R. T. Bartus, and E. Friedman (1981) Presynaptic cholinergic mechanisms in brains of aged rats with memory impairments. Neurobiol. Aging 2: 99-104.

Sims, N. R., K. L. Marek, D. M. Bowen, and A. N. Davison (1982) Production of $\left({ }^{14} \mathrm{C}\right)$ acetylcholine and $\left({ }^{14} \mathrm{C}\right)$ carbon dioxide from (U${ }^{14} \mathrm{C}$ ) glucose in tissue prisms from aging rat brain. J. Neurochem. 38 : $488-492$.

Strong, R., P. Hicks, L. Hsu, R. T. Bartus, and S. J. Enna (1980) Agerelated alterations in the rodent brain cholinergic system and behavior. Neurobiol. Aging 1: 59-63.

Sutherland, R. J., B. Kolb, and I. Q. Wishaw (1982a) Spatial mapping: Definite disruption by hippocampal or medial frontal cortical damage in the rat. Neurosci. Lett. 31: 271-276.

Sutherland, R. J., I. Q. Wishaw, and J. C. Regehr (1982b) Cholinergic receptor blockade impairs spatial localization using distal cues in the rat. J. Comp. Physiol. Psychol. 96: 563-573.

Sutherland, R. J., I. Q. Wishaw, and B. Kolb (1983) A behavioral analysis of spatial localization following electrolytic, kainate-, or colchicine-induced damage to the hippocampal formation in the rat. Behav. Brain Res. 7: 133-153.

Wishaw, I. Q. (1985) Evidence for two types of place navigation in the rat. In Electrical Activity of the Archcortex, G. Buzsaki and C. $\mathrm{H}$. Vanderwolf, eds., Hungarian Academy of Sciences, Budapest.

Wishaw, I. Q., and B. Kolb (1984) Decortication abolishes place but not cue learning in rats. Behav. Brain Res. 11: 123-134.

Wishaw, I. Q., W. T. Connor, and S. B. Dunnett (1985) Disruption of central cholinergic systems in the rat by basal forebrain lesions or atropine: Effects on feeding, sensorimotor behavior, locomotor activity and spatial navigation. Behav. Brain Res. 17: 103-115. 